under normal circumstances be recorded by our local coroner's office. In our efforts to resolve the difficulty, we encountered a more complete but less detailed source of data. In those districts where child health surveillance and school health records are computerised, a comprehensive list is kept of children who have died in order that grieving parents are not inadvertently sent invitations to attend child health surveillance appointments. The list is usually complete and includes loca residents who have died outside of the distric boundaries. The information contained in these lists usually just extends to the child's name, address, and cause of death with no further details. However, we found these records of use in supplementing data supplied by the coroner's records.

We would concur with Dr Levene in her plea for a comprehensive prospectively compiled childhood accident mortality database. Coroners' inquisitions and child health records will yield basic data which might, perhaps, be usefully supplemented by confidential inquiries into the circumstances of individua accidents. Collation of locally relevant data is a key element in child accident prevention which should be a priority for every health authority.

$$
\begin{array}{r}
\text { M J BANNON } \\
\text { Child Accident Prevention Group, } \\
\text { North Staffordshire Health Authority, } \\
79 \text { London Road, } \\
\text { Stoke-on-Trent ST4 7PZ }
\end{array}
$$

1 Levene S. Coroners' records of accidental deaths. Arch Dis Child 1991;66:1239-41.

Subdural fat effusion complicating parenteral nutrition

SIR,-Rushforth et al recently reported an unusual complication of parenteral nutrition via a Silastic catheter. ${ }^{1}$ They stated the catheter was probably in the external jugular vein presumably based on a plain film of the head and neck.

It seems to me that this assumption is unfounded, principally because the catheter would not advance past $9 \mathrm{~cm}$. In my experience this is caused by the catheter wedging in a small vessel. It would thus seem more likely that the catheter had found its way via the deep temporal vein into the anterior diploic vein with free communication to meningeal veins. ${ }^{2}$ Rupture of these veins would result in a subdural collection.

In my opinion the message of the paper of Rushforth et al should be that if a Silastic catheter will not advance, it is probably wedged in a small vein. The catheter should therefore be withdrawn $i$ or $2 \mathrm{~cm}$ before readvancing. If this fails the tip should be left one centimetre proximal to the site of obstruction and thus presumably in a larger vein.

$$
\begin{array}{r}
\text { SW JONES } \\
\text { Department of Paediatrics, } \\
\text { Princess Margaret Hospital, } \\
\text { Okus Road, } \\
\text { Swindon, } \\
\text { Wiltshire SNI 4JUU }
\end{array}
$$

1 Rushforth A, Green MA, Levene MI, Puntis JWL. Subdural fat effusion complicating 1350-1.

2 Williams PL, Warwick R. Cranial and intracranial veins. Gray's anatomy. 36th Ed Edinburgh: Churchill Livingstone, 1980.
Dr Rushforth and colleagues comment:

We note Dr Jones' suggestion of a possible route of a percutaneous central venous catheter, via diploic veins, to lie in the middle meningeal vein to explain a subdural collection. However, the diploic veins are absent at birth and do not develop until around 2 years of age. ${ }^{1}$ The infant in the case report was still less than 37 weeks' corrected gestational age at the time of the incident. ${ }^{2}$

It may be possible to suppose passage of a catheter via an emissary vein to lie in the sigmoid sinus. However, this route is tortuous and would not be supported by the appearance on the original radiograph.

We agree that if a catheter will not advance, it is probably lodged in a small vein and should be withdrawn. Free flow of blood back through the catheter would support its tip being in a large vein, as the case in our report. ${ }^{2}$ However, the ideal position for central venous catheters should be the right atrium where risk of retrograde flow is less.

1 Williams PL, Warwick R, Dyson M, Bannister LH, eds. Angiology. Grays anatomy. 37th Ed. London: Churchill Livingstone, 1989:798-805. 2 Rushforth $A$, Green MA, Levene $M$, Puntis JWL. Subdural fat effusion complicating parenteral nutrition. Arch Dis Child 1991;66:
1350-1.

\section{Health for all children}

SIR,-The importance of early diagnosis of biliary atresia has been stressed repeatedly by hepatologists and is now acknowledged by those responsible for child health surveillance programmes.' However, it does seem premature to suggest that we should change the age at which the infant's first formal postnatal review is performed, ${ }^{2}$ particularly as the revised programme of child health surveillance recommends that this review should be com bined with the first immunisation at the age of 8 weeks. $^{3}$

Each district in the UK will produce one new case of biliary atresia every four or five years. We need to know what strategies would be best to achieve early detection of such a rare condition. Formal screening may be less effective than professional education combined with easy rapid access to the appropriate tests and the expertise to interpret them. The paediatric hepatology team at King's College Hospital is uniquely well placed to determine what work load would result, and what unforeseen problems might arise, if the various strategies they propose were to be implemented. Our experience with neonatal screening for hearing loss has taught us how much effort and commitment are required to make such programmes work effectively, even when run by an enthusiast.

DAVID M B HALL Department of Community Child Health, Clare House, St George's Hospital,

1 Hall DMB. Health for all children. 2nd Ed. Oxford: Oxford University Press, 1992:44.

2 Hussein M, Howard ER, Mieli-Vergani G, Mowat AP. Jaundice at 14 days of age: exclude biliary atresia. Arch Dis Child 1991;66:1177-9.

3 Hall DMB. Health for all children. 2nd Ed. Oxford: Oxford University Press, 1992:125-6.

$$
\text { Royal Liverpool Children's Hospital, }
$$

LIZABETH MOLYNEUX Myrtle Street,
Liverpool $L 77 G G$

\section{Intraosseus infusion}

SIR,-The intraosseous route for emergency infusions of fluids and drugs is underutilised in this country and Drs Ryder, Munro, and Doull do well to remind us of its simplicity and efficacy when vascular access is difficult and speed essential. ${ }^{1}$ However, when discussing the various sites for intraosseous infusion they include the sternum. This site is too hazardous to recommend in my opinion. The upper tibial shaft is safe and favoured as the intraosseus infusion site of first choice by most emergency physicians. The lower end of the femur or humerus are other useful alternatives.

Specially designed intraosseous needles are available and have a shelf life of approximately shafted needles (for example a large butterfly or needle of large bore intravenous cannula) is that they are less likely to become blocked by bone particles and can more easily be anchored in situ. Their cost is not prohibitive (about $£ 10-£ 15$ each) and it would seem appropriate for all emergency trolleys or boxes to include such needles. One size, either a 16 or 18 , is usable in most situations for all ages of children. Liverpool L7 TGG

1 Ryder IG, Munro HM, Doull IJM. Intraosseous infusion. Arch Dis Child 1991;66:1442-3.

\section{Familial asplenia}

SIR,-We read the article on haemophilus septicaemia in congenital asplenia ${ }^{1}$ and the interest. We would like to describe our experience, which illustrates the importance of familial asplenia and also a potential disadvantage of not performing a necropsy.

A 21 month old girl, the second child of non-consanguineous white Australian parents presented to a peripheral hospital with a short history of fever and delirium. She was profoundly shocked with widespread purpura and ecchymoses. A presumptive diagnosis of meningococcaemia was made, resuscitation with artificial ventilation, antibiotics and plasma was commenced, and transfer to this hospital was requested. On arrival here she was moribund and died within minutes. Blood cultures were sterile. Necropsy was requested but declined by the distraught parents.

The parents subsequently had a third child, a boy, who presented at the age of 4 months with fever and rapid onset of shock and purpura. He was found to have purpura distal limbs, ears and nose, and with purpura on his lips. Cultures of blood and cerebrospinal fluid grew Streptococcus pneumoniae. Blood films showed numerous erythrocytes containing Howell-Jolly bodies. An ultrasound scan revealed no spleen and asplenia was confirmed by technetium scan. Cardiac ultrasound scan was normal. His sister's original blood film was retrieved from the peripheral hospital and the red cells were also found to contain many Howell-Jolly bodies. The oldest child is well, has a normal peripheral blood film, and has a spleen on ultrasound.

The patient required intensive resuscitation with artificial ventilation, colloid, blood, and five years. Their advantage over using hollow subsequent correspondence ${ }^{23}$ with great fulminans, with confluent ecchymoses of his 
inotropes. He developed peripheral gangrene, requiring amputation of the fingers but no thumb of his left hand to the metacarpophalangeal joints, amputation of his right fingers to the proximal interphalangeal joints amputation of all his toes, and removal of necrotic tissue and bone on his left heel. He had extensive skin grafting to the lower limbs. Good function of his right hand was predicted He was discharged on prophylactic antibiotics. Polyvalent pneumococcal vaccine and meningococcal vaccine will be given at 24 months and conjugate vaccine against Haemophilus influenzae type b as soon as it is available in Australia.

These siblings presumably have recessively inherited congenital asplenia and normal hearts. Hereditary splenic hypoplasia was first described in three of five siblings by Kevy $e t$ $a l .{ }^{4}$ In a review of 60 children with asplenia or polysplenia from Toronto, there were two families in which two siblings had isolated asplenia and one family in which two siblings had polysplenia.

It was assumed that our first patient died of meningococcal sepsis, although in retrospect she may have had pneumococcal sepsis, as both organisms may sometimes fail to grow from severe cases. In an ideal world, a necropsy would have been performed, would have revealed asplenia and we would have screened the next child at birth. Prophylactic antibiotics have been shown to be effective in reducing the incidence of bacterial sepsis in children with congenital asplenia, ${ }^{6}$ and immunisations as already described could have been given at the appropriate age.

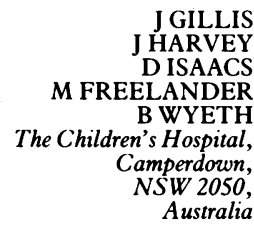

1 Dyke MP, Martin RP, Berry PJ. Septicaemia and adrenal haemorrhage in congenital asplenia. Arch Dis Child 1991;66:636-7.

2 Gill -DG, Kara M. Septicaemia and adrena haemorrhage in congenital asplenia. Arch Dis Child 1991;66:1366.

3 Moore L. Septicaemia and adrenal haemorrhage in congenital asplenia. Arch Dis Child 1991;66: in congenit.

4 Kevy SV, Tefft M, Vawter GF, Rosen FS Hereditary splenic hypoplasia. Pediatrics 1968 ; 42:752-7.

5 Rose V, Izukawa T, Moes CAF. Syndromes of asplenia and polysplenia. Br Heart $\mathcal{F}$ 1975;37: 840-52.

6 Biggar WD, Ramirez RA, Rose V. Congenital asplenia: immunologic assessment and a clinical review of eight surviving patients. Pediatrics 1981;67:548-51.

\section{Growth performance of affluent Indian} children under 5 years of age

SIR,-Paediatricians interested in the growth patterns of children of families originating from the Indian subcontinent may like to know of a study by the Nutrition Foundation of India on 'Growth performance of affluent Indian children (under fives)'.' The study was undertaken to determine whether the international growth standards developed by the National Center for Health Statistics in the USA were applicable to Indian children. A corollary to this was the desirability, or otherwise, of collecting data on Indian children on a national scale.

The authors accepted that socioeconomic and environmental factors and the malnutrition-infection complex rather than genetic factors were the main constraints determining the differences between the growth performance of children in developed and developing countries. ${ }^{2}$ In order to eliminate these factors as far as possible, only children from affluent families (they took some pains to define 'affluent') were studied in seven cities: two in the north (Ludhiana and Delhi), two in central India (Kota and Varanasi), one on the west coast (Bombay), one in the south (Bangalore), and one on the east coast (Calcutta).

The results showed that 'affluent' children ( $0-5$ years) in Ludhiana and Delhi in the north had attained a level of growth in height and weight which nearly corresponded to those of the international growth standards and it was therefore concluded that these standards could be used for Indian children. In the remaining cities where growth fell below the American standards it was thought that the explanation lay in the dietary differences between the various parts of India.

The value of this study is that paediatricians in Britain can use (or continue to use) the American or the Tanner-Whitehouse standards for the children of Indian origin in the important 0-5 year period. It must be emphasised, however, that these findings do not apply to the neighbouring countries of Pakistan, Bangladesh, Nepal, and Sri Lanka. Those interested in the details of the study should consult the original report.

JOHN BLACK 54 Ruskin Park House Champion Hill, London SE5 $8 T Q$

1 Agarwal KN, Agarwal DG, Benakappa SM, et al. Growth performance of affluent Indian children (under fives). New Delhi: Nutrition Foundation of India (scientific report 11), 1991. (Available in the Library

2 Anonymous. A measure of agreement on growth standards [Editorial]. Lancet 1984;i:142-3.

\section{Birthweight ratio in public health}

SIR,-A similar birthweight ratio to that used for guidance in sophisticated neonatal intensive care discussed by Dr Lucas $e t a l^{1}$ has been suggested as a public health indicator. This was termed the 'socioeconomic birth weight [b wt] quotient' (or ratio). ${ }^{2}$ It was defined as:

average $b$ wt low socioeconomic population average $b$ wt upper socioeconomic population $\times 1000$

It was considered as a rough potential cumulative measure of 'social development', especially of prenatal care, maternal nutrition, and infections (notably placental malaria ${ }^{3}$ ).

This approach is only valid when the community concerned is, in general, genetically uniform. Also, as always with such comparisons, problems occur in defining the two groups. Generally well nourished, genetically homogeneous communities with good prenatal services, as in Denmark, should have an index of 1000 . In a study in an area in India, results ranged from 872 to 885 .

DERRICK JELLIFFE PATRICE JELLIFFE School of Public Health, University of Califormia (UCLA), 10833 Le Conte Avenue, Los Angeles,
1 Lucas A, Morley R. Birthweight ratio. Arch Dis Child 1991;66:1099.

2 Jelliffe DB, Jelliffe EFP. The socio-economic birth weight quotient. In: Sterky G, Mellander L, eds. Birthweight distribution: an indicator of social development. Report No 8. Stockholm: SAREC, 1978:41-3.

3 Jelliffe EFP. Low birth weight and malarial infection of the placenta. Bull World Health Organ 1968;38:69-73.

4 Jelliffe EFP. Materno-fetal malaria: multiple dyadic dilemmas. Geneva: World Health Organisation (in press)

5 Prema K. Pregnancy and lactation: some nutritional aspects. Indian $\mathcal{F}$ Med Res 1978;68: 78-82.

\section{Toxic shock-like syndrome due to Streptococcus pyogenes}

SIR,-Streptococcal toxic shock syndrome has been recently reported in both adults ${ }^{1-3}$ and children. ${ }^{4}$ Torres-Martinez et al described four children all of whom survived but required intensive treatment and aggressive cardiovascular resuscitation. ${ }^{5}$ Reports in adults have often demonstrated less favourable outcomes despite appropriate management. Our recent experience with one child would agree with this

A previously well, 5 year old boy was admitted to Crawley Hospital with a two day history of cough and sore throat. He developed inspiratory and expiratory stridor three hours after admission becoming distressed and requiring nasotracheal intubation. The epiglottis was normal but there was evidence of a tracheitis; a tracheal aspirate grew group A $\beta$ haemolytic stretococcus but blood cultures were negative. $\mathrm{He}$ was given intravenous benzylpenicillin, flucloxacillin, and cefotaxime. Thirty six hours later he was extubated but after 12 hours he suddenly deteriorated and required reintubation. At that time a chest radiograph showed partial collapse of the left lower lobe. He was transferred to the Royal Alexandra Hospital for Sick Children at Brighton for further management and on arrival 72 hours after his original hospital admission his condition was stable. His full blood count, haemoglobin, urea, and electrolyte concentrations, and blood gases were all normal. His blood pressure was $100 / 50 \mathrm{~mm}$ $\mathrm{Hg}$. Intravenous benzylpenicillin was continued in a dose of $150 \mathrm{mg} / \mathrm{kg} /$ day in four divided doses and after discussions with the microbiology laboratory gentamicin $40 \mathrm{mg}$ every eight hours and chloramphenicol 500 mg every six hour were added. A chest radiograph shortly after admission showed considerable improvement. Twelve hours after admission, while fully ventilated, he suddenly became hypotensive, bradycardic, and hypoxic, the deterioration being associated with evacuation of his bowels. The heart rate fell from 120 to 40 per minute and the oxygen saturation from 96 to $40 \%$. Despite $80 \mathrm{ml} / \mathrm{kg}$ of colloid followed by a continuous infusion, intravenous adrenaline $2 \mathrm{ml}$ of 1:10 $000 \times 3$, a dopamine infusion, and intravenous atropine $200 \mu \mathrm{g} \times 2$, he deteriorated further. His liver enlarged to $5 \mathrm{~cm}$ below the right costal margin and he developed disseminated intravascular coagulation and renal failure. He died 17 hours later. Postmortem examination revealed only a hyperaemic trachea and bronchi. There were small bilateral pleural effusions. The National Reference Laboratory (Colindale) reported an antistreptolysin-O titre of 400 units $/ \mathrm{ml}$, an anti-DNAse B titre of 180 units/ $\mathrm{ml}$, and an antihyaluronidase activity of 1024 units $/ \mathrm{ml}$. The streptococcus isolated from the 